\title{
Article \\ Sub- and Supercritical Extraction of Slovenian Hops (Humulus lupulus L.) Aurora Variety Using Different Solvents
}

\author{
Katja Bizaj $^{1}\left(\mathbb{D}\right.$, Mojca Škerget $^{2}$ (D), Iztok Jože Košir ${ }^{3}(\mathbb{D})$ and Željko Knez ${ }^{2,4, *(\mathbb{D})}$ \\ 1 Hmezad exim d.d., Vrečerjeva ulica 14, SI-3310 Žalec, Slovenia; k.bizaj@gmail.com \\ 2 Laboratory for Separation Processes and Product Design, Faculty of Chemistry and Chemical Engineering, \\ University of Maribor, Smetanova 17, SI-2000 Maribor, Slovenia; mojca.skerget@um.si \\ 3 Slovenian Institute of Hop Research and Brewing, Cesta Žalskega Tabora 2, SI-3310 Žalec, Slovenia; \\ iztok.kosir@ihps.si \\ 4 Department of Chemistry, Faculty of Medicine, University of Maribor, Taborska 8, SI-2000 Maribor, Slovenia \\ * Correspondence: zeljko.knez@um.si
}

Citation: Bizaj, K.; Škerget, M.; Košir

I.J.; Knez, Ž. Sub- and Supercritical

Extraction of Slovenian Hops (Humulus lupulus L.) Aurora Variety Using Different Solvents. Plants 2021, 10, 1137. https://doi.org/10.3390/ plants10061137

Academic Editor: Petko Denev

Received: 22 April 2021

Accepted: 31 May 2021

Published: 3 June 2021

Publisher's Note: MDPI stays neutral with regard to jurisdictional claims in published maps and institutional affiliations.

Copyright: () 2021 by the authors. Licensee MDPI, Basel, Switzerland. This article is an open access article distributed under the terms and conditions of the Creative Commons Attribution (CC BY) license (https:// creativecommons.org/licenses/by/ $4.0 /)$.

\begin{abstract}
This work investigates the efficiency of supercritical fluid extraction of hops with a variety of solvents including carbon dioxide $\left(\mathrm{CO}_{2}\right)$, propane, sulfur hexafluoride $\left(\mathrm{SF}_{6}\right)$, and dimethyl ether (DME) at various densities (low-density and high-density). Operating parameters were 50 bar, 100 bar and 150 bar and $20^{\circ} \mathrm{C}, 40{ }^{\circ} \mathrm{C}, 60^{\circ} \mathrm{C}$ and $80^{\circ} \mathrm{C}$ for all solvents, respectively. The influence of process parameters on the total yield of extraction and content of bitter acids in the extracts has been investigated. The mathematical model based on Fick's second law well described the experimental extraction results. Furthermore, HPLC analysis has been used to determine $\alpha$-and $\beta$-acids in extracts. The yield of bitter compounds in hop extracts was largely influenced by the type of solvent, the temperature and pressure applied during extraction. The results show that $\mathrm{CO}_{2}$ and propane were roughly equivalent to DME in solvating power, while $\mathrm{SF}_{6}$ was a poor solvent at the same conditions. The highest yield as well as the highest concentration of bitter acids in extracts were obtained by using DME, where the optimal operating conditions were $40{ }^{\circ} \mathrm{C}$ and 100 bar for the extraction of $\alpha$-acids (max. concentration $9.6 \%$ ), $60{ }^{\circ} \mathrm{C}$ and 50 bar for the extraction of $\beta$-acids $(4.5 \%)$ and $60{ }^{\circ} \mathrm{C}$ and 150 bar for the maximum extraction yield $(25.6 \%)$.
\end{abstract}

Keywords: hop extract; carbon dioxide; propane; sulfur hexafluoride; dimethyl ether; diffusion coefficient; bitter acids

\section{Introduction}

Hop (Humulus lupulus L.) is a dioecious, perennial climbing plant well-known for a long time due to its healing properties, bacteriostatic action and preservative qualities. It belongs to the Cannabinacea family and it is cultivated in temperate zones such as North America, West Asia and Europe [1,2]. The plant grows in excess of $6-7 \mathrm{~m}$ per season, producing a large amount of biomass [3]. The leaf and the steam material of the plant present approximately $75 \%$ of biomass produced by hop [4]. The harvested portion of the plant so called female inflorescence or hop cones are the most commonly used for various purposes in beverages and herbal medicine. In the cones of the female hop plant (termed lupulin glands) a range of specific bioactive secondary metabolites, including prenylated flavonoids (xanthohumol and desmethylxanthohumol), bitter acids, phenolic compounds and essential oils are found [5]. Substances found in hop plants are commonly called resins.

For centuries hops have been famously known as a key ingredient of beer, but its medicinal properties have been studied over the last decades, when scientists all over the world started exploring the effects of healing plants. Several in vitro and in vivo studies have shown that hop flowers act as antifungal agents [6] and are used to relieve the symptoms of insomnia and stress [7]. Certain hop compounds also have the potential of becoming novel anticancer agents. The essential oil derived from hops is a mixture 
of more than 1000 compounds, including alcohols, terpenes, organic acids and phenolics $[8,9]$. Polyphenols have been studied as natural additives with antimicrobial and antioxidant properties.

Presently, $90 \%$ of global hop production is used by the brewing industry as a stabilising agent and to add bitterness and aroma to beer [10]. In particular, the hop's resins and essential oils are responsible for its characteristic aroma [11,12]. However, whilst brewing, it is crucial to prevent oxidation, once $\alpha$-acids oxidize, they can no longer be isomerized into iso- $\alpha$-acids leading to an unpleasant aroma and decreased bittering potential. One solution is to use hop extracts, which have many advantages. Extracts are more homogeneous than hop powder or hop pellets, have improved hop utilization, better bitterness control, improved stability on storage and reduced transport and storage costs [13].

Bitter acids are usually classified as $\alpha$-acids and $\beta$-acids. $\alpha$-acids are humulone (35-70\% of total $\alpha$-acids), cohumulone (20-65\% of total $\alpha$-acids) and adhumulone (10-15\% of total $\alpha$-acids). The substances known as $\beta$-acids include lupulone (30-55\% of total $\beta$-acids), colupulone and adlupulone [14-16]. Both the $\alpha$ - and $\beta$-acids are very prone to oxidation and chemical deterioration. To prevent this, proper storage of hops is critical, requiring an oxygen barrier and refrigeration between $0{ }^{\circ} \mathrm{C}$ and $5^{\circ} \mathrm{C}$ [17].

Levels of $\alpha$ - and $\beta$-acids in hop products depend on the hop variety, climate, soil, environmental factors at harvest and cultivation conditions [18-20]. In commercial use, the hop products are divided in seven groups: hop powder/pellets, enriched hop powder/pellets, speciality hop powder/pellets (made by mixing hop powder/pellets with other substances intended to improve stability), hop extract, isomerized hop products and hop oil [21]. Several scientific papers deal with the sub- and supercritical extraction of hop, using various gases as extracting solvents. The first example dates back to the late 1970s describing the use of $\mathrm{CO}_{2}$ in liquid or supercritical form. With respect to the choice of appropriate solvent and extraction procedure, several modifications have been reported. Unconventional solvents, such as noble gases and their mixtures are opening new perspectives, but latter requires separation processes for removing potentially harmful solvent from the final product [22]. Those solvents need to be tightly controlled with respect to their residual levels. As solvents and their residues in extract have possible harmful effects for humans, less attention has been paid to them and there is less literature data about their use for extraction of hops under sub- and supercritical conditions. However, selection of a supercritical fluid is crucial for the development of efficient supercritical fluid extraction (SFE) process.

Restrictions in the use of organic solvents, easy penetration of organic matter, and high solvating power, has meant that carbon dioxide has begun to move from some marginal applications to becoming the major solvent used for SFE processes. More than $90 \%$ of SFE studies have been performed with $\mathrm{CO}_{2}$ as the solvent [23]. Supercritical $\mathrm{CO}_{2}$ is a good solvent for the extraction of non-polar compounds such as hop soft resins, oil and aroma components, alcohols, aldehydes, olefins, paraffins, esters, amines, aromates, ketones, amides and nitrites, but its large quadrupole moment also enables it to dissolve some moderately polar compounds such as polyphenols [23-25]. Representatives of a large group of biologically active prenylflavonoids can also be present in the plant material. However, a cosolvent is required to extract these polar compounds.

Supercritical fluids such as Freon-22, nitrous oxide and hexane have been considered to extract polar compounds, but their applications are limited due to environmental and safety considerations. Superheated water has certain advantages such as higher extraction ability for polar compounds and products obtained in this way are solvent-free, however, it is not suitable for thermally labile compounds [26]. Several studies have also proposed compressed propane as a viable non-polar solvent and have shown good extraction yields and high antioxidant activity of extracts [27-32].

DME is known as a low-temperature and non-toxic solvent and to the best of our knowledge, there are no reports in the literature using this solvent as an extraction agent for hops. DME is partially miscible with water, which is an advantage not shared by other 
solvents such as propane and $\mathrm{CO}_{2}$. This allows processing of an aqueous feed stream and thus the need for drying of wet feed material is avoided. This represents a great advantage in hops industry where drying is costly and/or involves processing conditions that may degrade the material and alters the amount and chemical composition of the hop oils. DME is not a greenhouse gas and does not cause ozone depletion, also removing the solvent from the final product is simple and virtually complete [33].

Conversely, $\mathrm{SF}_{6}$ is an extremely potent and persistent greenhouse gas, it is nonflammable, and non-toxic, and considered as one of the heaviest known gases (its density is approximately five times higher than that of air). To date, only a few studies have been published that investigate its use as an extraction solvent. Phase equilibrium studies of vegetable oil- $\mathrm{SF}_{6}$ systems showed that as a high-pressure solvent $\mathrm{SF}_{6}$ shows higher solvent power for vegetable oils than $\mathrm{CO}_{2}$. Therefore, $\mathrm{SF}_{6}$ opens new perspectives as a highpressure liquid solvent $[34,35]$. Depending on the extraction conditions and technologies, different compositions of acids in the final product can be obtained [36]. Aurora is an aroma variety bred from the English variety Northern Brewer and Slovenian genetic hop germ-plasm. This variety is recognised for its excellent agronomic traits in hop production and processing. Aurora is known for its pleasant hop aroma and bitterness, which offers excellent brewing value.

The aim of our study was to determine efficiencies of sub- and supercritical extraction of Aurora variety Slovenian hops using fluids of different polarity. Hence, DME was selected as the polar solvent, and $\mathrm{CO}_{2}$, propane and $\mathrm{SF}_{6}$ were used as non-polar solvents. Under identical operating conditions the solvents were in different states. $\mathrm{CO}_{2}$ was a liquid at experimental temperatures lower than $40{ }^{\circ} \mathrm{C}$ while at $40{ }^{\circ} \mathrm{C}$ and higher it was supercritical. Propane and DME were liquid over the entire experimental range, while $\mathrm{SF}_{6}$ was liquid at temperatures lower than $60^{\circ} \mathrm{C}$ and supercritical at $60{ }^{\circ} \mathrm{C}$ and higher. After performing all experiments with all solvents, the difference in concentrations of $\alpha$-and $\beta$-acids in obtained extracts from hop pellets was observed. The mass transport coefficients, which are crucial for the design and scale-up of the extraction process, were also determined.

Extraction experiments were performed using a semi-continuous apparatus at pressures of 50 bar, 100 bar and 150 bar, and at temperatures of $20{ }^{\circ} \mathrm{C}, 40{ }^{\circ} \mathrm{C}, 60{ }^{\circ} \mathrm{C}$ and $80{ }^{\circ} \mathrm{C}$. The content of $\alpha$ - and $\beta$-acids in extracts was determined by high-performance liquid chromatography (HPLC) using a UV/VIS detector set at a wavelength of $314 \mathrm{~nm}$.

\section{Results and Discussion}

\subsection{Extraction Kinetics Study}

Semi-continuous operation mode was applied for extraction of oil from hops using different solvents under the same operating conditions. This technique, also termed semibatch or semi-flow, is a process in which one phase flows continuously through a vessel containing a batch of another phase. Extensive physical contact between the solvent and the bed of hop particles was thus achieved. In the extractor, the oils in the hops were dissolved in the solvent and the target product (hop extract) was trapped in the precipitation unit. The extraction yield was calculated as the mass of the oil extracted by the mass of raw material fed into the extractor. Extraction kinetic curves for extraction of oil from hops with dense $\mathrm{CO}_{2}$ at different operating conditions are presented in Figure 1 (data given in Tables 1 and 2). The obtained results can be explained by considering the density of the fluid and diffusivity of solute in the fluid. At constant temperature, the density and the solvent power of the fluid increase with increasing pressure, while the diffusivity decreases. Conversely, at constant pressure the density decreases with increasing temperature while the diffusivity increases. From Figure 1 it can be observed generally that at constant temperature the extraction yield and extraction rate increase with increasing pressure from 100 bar to 150 bar, while at constant pressure the total yield and extraction rate decrease with increasing temperature from $40{ }^{\circ} \mathrm{C}$ to $80^{\circ} \mathrm{C}$. This is in accordance with the variation of density of $\mathrm{CO}_{2}$ and its solvent power with temperature and pressure. This 
behavior is similar to that obtained by Campos et al. [37] and del Valle et al. [38] for the extraction of Calendula officinalis and Humulus lupulus L., respectively. An exception is observed at 150 bar and temperatures between $20^{\circ} \mathrm{C}$ and $40^{\circ} \mathrm{C}$, where the course of both isotherms is similar in the stage of constant extraction rate while in the stage of decreasing extraction rate the yield and also extraction rate are somewhat higher at $40{ }^{\circ} \mathrm{C}$. This is probably a consequence of higher diffusivity and higher vapor pressure of solute at higher temperature. These phenomena were also perceived by Vargas et al. [39], Zancan et al. [40] and Sovová et al. [41] for extraction of Carqueja essential oil, Zingiber officinale Roscoe and Piper nigrum L., respectively. The highest yield $(12.2 \%)$ was obtained at $40{ }^{\circ} \mathrm{C}$ and extraction process required approximately $100 \mathrm{~kg} \mathrm{CO}_{2} / \mathrm{kg}$ hops. The yields were similar to those obtained by del Valle et al. [38] for Nugget variety $\left(13.9 \%\right.$ at 200 bar and $50{ }^{\circ} \mathrm{C}$ ) and data obtained by Langezaal et al. [42] and Kupski et al. [21] under similar conditions. At $80^{\circ} \mathrm{C}$ and 150 bar, the yield was very low as a result of the weak solvent power at lower densities.

In Figure 2, the kinetics of semi-continuous extraction of oil from hops with DME at different operating conditions is presented. By comparing Figures 1 and 2 it can be seen, that in the case of DME the total yields were generally much higher than in the case of $\mathrm{CO}_{2}$ and ranged from 23 to $26 \%$, while solvent consumption was much lower than for $\mathrm{CO}_{2}$, and at the maximum yield of $25.6 \%$ (150 bar and $60^{\circ} \mathrm{C}$ ) it was only approximately $40 \mathrm{~kg} \mathrm{DME} / \mathrm{kg}$ hops. Furthermore, the course of the isotherms at temperatures ranging from $60{ }^{\circ} \mathrm{C}$ to $80^{\circ} \mathrm{C}$ and pressures from 100 bar to 150 bar is similar, indicating that at these conditions, temperature and pressure have little influence on the extraction rate and extraction yield.

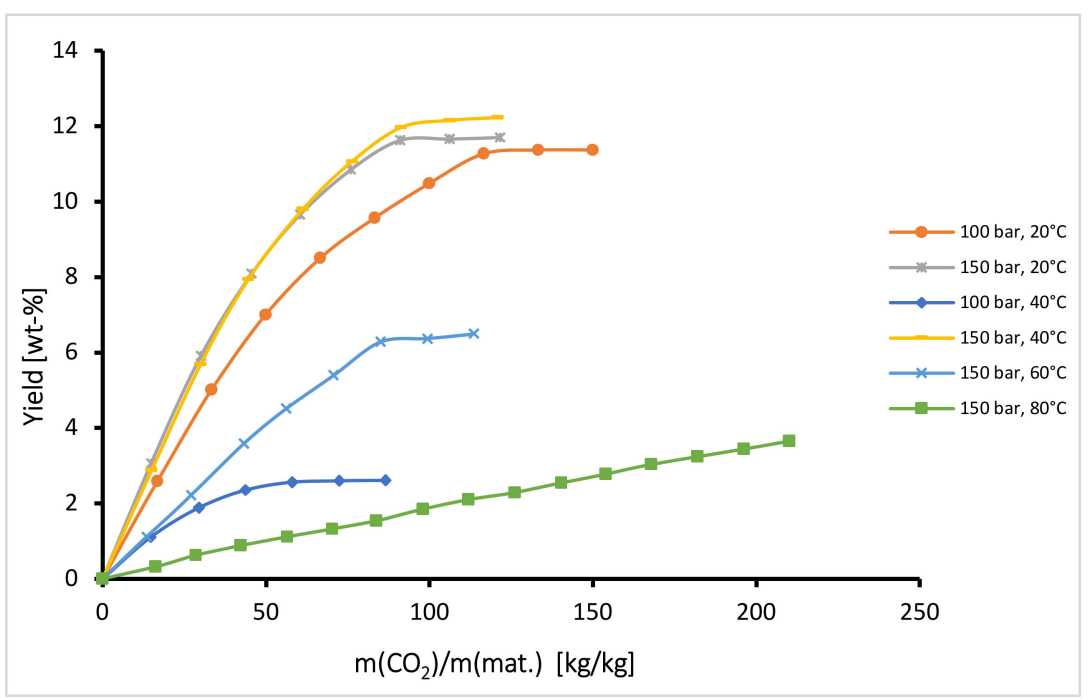

Figure 1. Kinetics of semi-continuous extraction of hops with dense $\mathrm{CO}_{2}$.

When using propane as solvent, the total yields ranged between 13\% to $19 \%$, shown in the Figure 3. At $20^{\circ} \mathrm{C}$, extraction rates and extraction yields were generally low over the entire pressure range, and rates decreased with increasing pressure from 50 bar to 100 bar and stayed approximately constant with further pressure increases. At higher temperatures, the opposite trend was observed. At $40{ }^{\circ} \mathrm{C}$ the extraction rates and extraction yields increased with increasing pressure over the pressure range, while at $60^{\circ} \mathrm{C}$ and $80^{\circ} \mathrm{C}$ the rates and yields increased with increasing pressure from 50 bar to 100 bar and stayed approximately constant with further pressure increases. At constant pressure the extraction rates and extraction yields generally increased with increasing temperature to $60^{\circ} \mathrm{C}$ and afterwards decreased with further increasing temperature to $80^{\circ} \mathrm{C}$. The max. yields at all investigated pressures were obtained at $60^{\circ} \mathrm{C}$ and the values at $100 \mathrm{bar}$ and $150 \mathrm{bar}$ were similar and the highest (18.7\%). It was noted that propane yielded higher extraction rates than carbon dioxide. These results are similar to a study by Veiga et al. [43] showing a 
positive effect of temperature and a negative effect of pressure on the extraction yield of Brazilian Mantiqueira hops with compressed propane (the highest yield was obtained at $60{ }^{\circ} \mathrm{C}$ and 100 bar and it was $\left.6.0 \mathrm{wt}-\%\right)$.

Table 1. Model adjustable parameters for extraction of hops with respect to experimental conditions.

\begin{tabular}{|c|c|c|c|c|c|c|c|c|}
\hline Solvent & $\begin{array}{c}\mathrm{T} \\
{\left[{ }^{\circ} \mathrm{C}\right]}\end{array}$ & $\begin{array}{c}p \\
{[\text { bar] }}\end{array}$ & $\begin{array}{c}\rho^{*} \\
{\left[\mathrm{~kg} / \mathrm{m}^{3}\right]}\end{array}$ & $\begin{array}{c}k_{1} * * \\
{[/]}\end{array}$ & $\begin{array}{c}k_{3} * * \\
{[/]}\end{array}$ & $\begin{array}{c}D_{1} \times 10^{7} * * * \\
{\left[\mathrm{~m}^{2} / \mathrm{s}\right]}\end{array}$ & $\begin{array}{c}D_{2} \times 10^{8 * * *} \\
{\left[\mathrm{~m}^{2} / \mathrm{s}\right]}\end{array}$ & $\begin{array}{c}A A R D^{* * * *} \\
{[\%]}\end{array}$ \\
\hline \multirow{6}{*}{$\mathrm{CO}_{2}$} & 20 & 100 & 856.3 & 0.533 & 0.075 & 0.155 & / & 1.66 \\
\hline & 20 & 150 & 904.0 & 1.255 & 0.074 & 0.248 & / & 0.88 \\
\hline & 40 & 100 & 628.6 & 0.184 & 0.786 & 0.252 & / & 1.99 \\
\hline & 40 & 150 & 780.2 & 1.254 & 0.046 & 0.243 & / & 7.77 \\
\hline & 60 & 150 & 604.1 & 0.673 & 0.385 & 0.153 & / & 5.19 \\
\hline & 80 & 150 & 427.2 & 0.619 & 0.387 & 0.039 & / & 4.09 \\
\hline \multirow{12}{*}{ Propane } & 20 & 50 & 510.8 & 0.767 & 0.318 & 0.216 & 0.006 & 2.51 \\
\hline & 20 & 100 & 521.3 & 0.161 & 0.852 & 0.220 & 0.566 & 3.38 \\
\hline & 20 & 150 & 530.2 & 0.012 & 0.957 & 0.299 & 0.417 & 3.48 \\
\hline & 40 & 50 & 481.2 & 0.007 & 0.963 & 0.379 & 0.384 & 1.81 \\
\hline & 40 & 100 & 495.5 & 0.007 & 1.095 & 0.413 & 0.630 & 13.1 \\
\hline & 40 & 150 & 506.9 & 0.739 & 0.134 & 0.202 & 0.032 & 0.46 \\
\hline & 60 & 50 & 446.4 & 0.391 & 0.260 & 0.449 & 0.817 & 0.33 \\
\hline & 60 & 100 & 467.2 & 0.651 & 0.241 & 0.537 & 0.681 & 0.35 \\
\hline & 60 & 150 & 482.1 & 0.640 & 0.063 & 0.547 & 0.059 & 3.56 \\
\hline & 80 & 50 & 400.9 & 0.414 & 0.262 & 0.405 & 0.063 & 1.81 \\
\hline & 80 & 100 & 435.2 & 0.637 & 0.326 & 0.422 & 0.011 & 2.96 \\
\hline & 80 & 150 & 455.6 & 0.606 & 0.327 & 0.516 & 0.422 & 1.38 \\
\hline \multirow{9}{*}{ DME } & 40 & 50 & 630.3 & 1.059 & 0.008 & 0.291 & 0.116 & 1.62 \\
\hline & 40 & 100 & 635.3 & 0.332 & 0.428 & 0.344 & 0.745 & 0.70 \\
\hline & 40 & 150 & 639.8 & 0.627 & 0.037 & 0.545 & 1.270 & 0.53 \\
\hline & 60 & 50 & 592.7 & 0.894 & 0.129 & 0.726 & 0.196 & 0.81 \\
\hline & 60 & 100 & 599.7 & 1.259 & 0.057 & 0.729 & 0.445 & 3.00 \\
\hline & 60 & 150 & 606.5 & 0.927 & 0.027 & 0.736 & 0.329 & 0.11 \\
\hline & 80 & 50 & 549.1 & 1.379 & 1.090 & 0.624 & 0.205 & 0.38 \\
\hline & 80 & 100 & 560.1 & 0.885 & 0.073 & 0.628 & 0.209 & 1.13 \\
\hline & 80 & 150 & 571.2 & 0.987 & 0.126 & 0.657 & 0.234 & 1.35 \\
\hline \multirow{11}{*}{$\mathrm{SF}_{6}$} & 20 & 50 & 1469.7 & 0.936 & 0.024 & 0.067 & 0.586 & 8.90 \\
\hline & 20 & 100 & 1545.8 & 0.657 & 0.251 & 0.073 & 0.200 & 4.14 \\
\hline & 20 & 150 & 1598.0 & 0.810 & 0.394 & 0.078 & 0.286 & 2.65 \\
\hline & 40 & 50 & 1273.4 & 0.935 & 0.148 & 0.056 & 0.063 & 9.10 \\
\hline & 40 & 100 & 1419.9 & 0.501 & 0.438 & 0.294 & 0.239 & 1.20 \\
\hline & 40 & 150 & 1495.4 & 0.695 & 0.416 & 0.312 & 0.205 & 3.60 \\
\hline & 60 & 50 & 753.3 & 0.935 & 0.042 & 0.051 & 0.043 & 3.62 \\
\hline & 60 & 100 & 1269.2 & 0.577 & 0.508 & 0.936 & 0.162 & 0.06 \\
\hline & 60 & 150 & 1383.9 & 0.996 & 0.078 & 0.966 & 0.162 & 4.90 \\
\hline & 80 & 100 & 1085.7 & 0.740 & 0.571 & 0.813 & 0.050 & 3.30 \\
\hline & 80 & 150 & 1263.1 & 0.510 & 0.297 & 0.789 & 0.831 & 1.14 \\
\hline
\end{tabular}

* Density of solvent obtained from NIST Chemistry WebBook ${ }^{47}$ at constant temperature $(T)$ and pressure $(P)$. Density for DME was obtained from Aspen Plus using Peng-Robinson EOS. ${ }^{* *}$ Fractions desorbed at a fast rate $\left(k_{1}\right)$ and desorbed at a slower rate $\left(k_{3}\right)$. ${ }^{* *}$ Diffusion coefficients $D_{1}$ and $D_{2}\left(\mathrm{~m}^{2} / \mathrm{s}\right)$. ${ }^{* * *}$ Average absolute relative deviation (\%). 
Table 2. Content of $\alpha$ and $\beta$-acids in extract expressed in weight $\%$ (mean \pm SD) and the yield of acids. (Limit of quantification $\operatorname{LoQ}=0.1 \%$ ).

\begin{tabular}{|c|c|c|c|c|c|c|c|}
\hline Solvent & $\begin{array}{c}\mathrm{T} \\
{\left[{ }^{\circ} \mathrm{C}\right]}\end{array}$ & $\begin{array}{c}P \\
{[\text { bar] }}\end{array}$ & $\begin{array}{c}\text { Yield * } \\
{[\%]}\end{array}$ & $\begin{array}{c}\text { Yield }_{(\alpha-a c i d s)}^{* *} \\
{[\%]}\end{array}$ & $\begin{array}{c}\text { Yield }_{(\beta-\text { acids })}^{* *} \\
{[\%]}\end{array}$ & $\begin{array}{c}W_{(\alpha-a c i d s)}^{* * *} \\
{[\%]}\end{array}$ & $\begin{array}{c}W_{(\beta-a c i d s)}^{* * *} \\
{[\%]}\end{array}$ \\
\hline \multirow{6}{*}{$\mathrm{CO}_{2}$} & 20 & 100 & 11.4 & 64.5 & 48.3 & $6.4 \pm 0.3$ & $2.4 \pm 0.1$ \\
\hline & 20 & 150 & 11.7 & 50.7 & 79.8 & $5.0 \pm 0.2$ & $3.8 \pm 0.2$ \\
\hline & 40 & 100 & 2.6 & 8.1 & 19.5 & $0.8 \pm<0.1$ & $0.9 \pm<0.1$ \\
\hline & 40 & 150 & $12.2 \pm 0.2 \mathrm{a}$ & 79.7 & 29.6 & $7.9 \pm 0.4$ & $1.4 \pm<0.1$ \\
\hline & 60 & 150 & 6.5 & 24.3 & 64.4 & $2.4 \pm 0.1$ & $3.0 \pm 0.1$ \\
\hline & 80 & 150 & 3.7 & 3.8 & 10.1 & $0.4 \pm<0.1$ & $0.5 \pm<0.1$ \\
\hline \multirow{12}{*}{ Propane } & 20 & 50 & 12.6 & 48.8 & 64.7 & $4.8 \pm 0.2$ & $3.0 \pm 0.1$ \\
\hline & 20 & 100 & 15.3 & 64.5 & 80.7 & $6.4 \pm 0.3$ & $3.8 \pm 0.2$ \\
\hline & 20 & 150 & 15.3 & 66.7 & 85.2 & $6.6 \pm 0.3$ & $4.0 \pm 0.2$ \\
\hline & 40 & 50 & 15.6 & 66.2 & 77.4 & $6.5 \pm 0.3$ & $3.6 \pm 0.2$ \\
\hline & 40 & 100 & 16.9 & 71.2 & 81.2 & $7.0 \pm 0.3$ & $3.8 \pm 0.2$ \\
\hline & 40 & 150 & 17.8 & 82.9 & 86.7 & $8.2 \pm 0.4$ & $4.1 \pm 0.2$ \\
\hline & 60 & 50 & 18.4 & 82.2 & 83.6 & $8.1 \pm 0.4$ & $3.9 \pm 0.2$ \\
\hline & 60 & 100 & 18.6 & 84.6 & 86.7 & $8.4 \pm 0.4$ & $4.1 \pm 0.2$ \\
\hline & 60 & 150 & $18.7 \pm 0.1 b$ & 87.6 & 90.5 & $8.7 \pm 0.4$ & $4.3 \pm 0.2$ \\
\hline & 80 & 50 & 14.3 & 62.3 & 57.4 & $6.1 \pm 0.3$ & $2.7 \pm 0.1$ \\
\hline & 80 & 100 & 16.1 & 55.8 & 66.4 & $5.5 \pm 0.2$ & $3.1 \pm 0.1$ \\
\hline & 80 & 150 & 16.9 & 58.5 & 61.9 & $5.8 \pm 0.3$ & $2.9 \pm 0.1$ \\
\hline \multirow{9}{*}{ DME } & 40 & 50 & 24.9 & 86.4 & 86.9 & $8.5 \pm 0.4$ & $4.1 \pm 0.2$ \\
\hline & 40 & 100 & 22.9 & 97.6 & 94.2 & $9.6 \pm 0.4$ & $4.4 \pm 0.2$ \\
\hline & 40 & 150 & 25.3 & 90.3 & 92.8 & $8.9 \pm 0.4$ & $4.4 \pm 0.2$ \\
\hline & 60 & 50 & 23.9 & 87.0 & 96.2 & $8.6 \pm 0.4$ & $4.5 \pm 0.2$ \\
\hline & 60 & 100 & 24.9 & 87.7 & 86.3 & $8.7 \pm 0.4$ & $4.1 \pm 0.2$ \\
\hline & 60 & 150 & $25.6 \pm 0.5 c$ & 84.6 & 84.9 & $8.3 \pm 0.4$ & $4.0 \pm 0.2$ \\
\hline & 80 & 50 & 24.7 & 49.7 & 61.7 & $4.9 \pm 0.2$ & $2.9 \pm 0.1$ \\
\hline & 80 & 100 & 24.0 & 52.9 & 66.0 & $5.2 \pm 0.2$ & $3.1 \pm 0.1$ \\
\hline & 80 & 150 & 23.5 & 59.9 & 74.8 & $5.9 \pm 0.3$ & $3.5 \pm 0.2$ \\
\hline \multirow{11}{*}{$\mathrm{SF}_{6}$} & 20 & 50 & 0.8 & 0.01 & $<0.01$ & $0.1 \pm<0.01$ & $<0.1 \pm<0.01$ \\
\hline & 20 & 100 & 0.7 & $<0.01$ & $<0.01$ & $<0.1 \pm<0.01$ & $<0.1 \pm<0.01$ \\
\hline & 20 & 150 & 0.6 & 0.01 & $<0.01$ & $0.1 \pm<0.01$ & $<0.1 \pm<0.01$ \\
\hline & 40 & 50 & 0.7 & 0.01 & $<0.01$ & $0.1 \pm<0.01$ & $<0.1 \pm<0.01$ \\
\hline & 40 & 100 & 0.7 & 0.01 & $<0.01$ & $0.1 \pm<0.01$ & $<0.1 \pm<0.01$ \\
\hline & 40 & 150 & 0.7 & $<0.01$ & $<0.01$ & $<0.1 \pm<0.01$ & $<0.1 \pm<0.01$ \\
\hline & 60 & 50 & 0.5 & 0.01 & $<0.01$ & $0.1 \pm<0.01$ & $<0.1 \pm<0.01$ \\
\hline & 60 & 100 & 0.7 & $<0.01$ & $<0.01$ & $<0.1 \pm<0.01$ & $<0.1 \pm<0.01$ \\
\hline & 60 & 150 & $0.9 \pm 0.01 \mathrm{~d}$ & $<0.01$ & $<0.01$ & $<0.1 \pm<0.01$ & $<0.1 \pm<0.01$ \\
\hline & 80 & 100 & 0.7 & $<0.01$ & 0.01 & $<0.1 \pm<0.01$ & $<0.1 \pm<0.01$ \\
\hline & 80 & 150 & 0.8 & 0.01 & 0.01 & $0.1 \pm<0.01$ & $0.1 \pm<0.01$ \\
\hline
\end{tabular}

${ }^{*}$ Extraction yield expressed in $w t \%, a, b, c, d$-based on triplicate experiments (mean \pm standard deviation). ${ }^{* *}$ Yield of $\alpha$ - and $\beta$-acids isolated regarding initial concentration of acids in raw material expressed in $\mathrm{wt} \%$. ${ }^{* * *}$ Concentration of $\alpha$ - and $\beta$-acids in extract expressed in $w t \%$ (mean \pm standard deviation). 


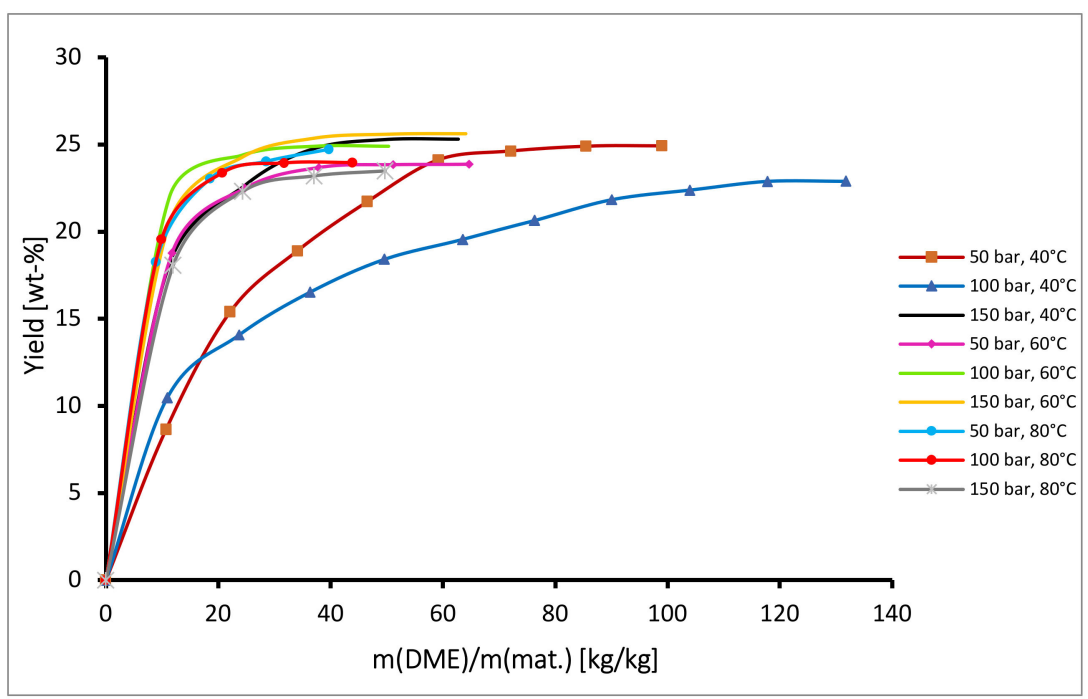

Figure 2. Kinetics of semicontinuous extraction of hops with DME.

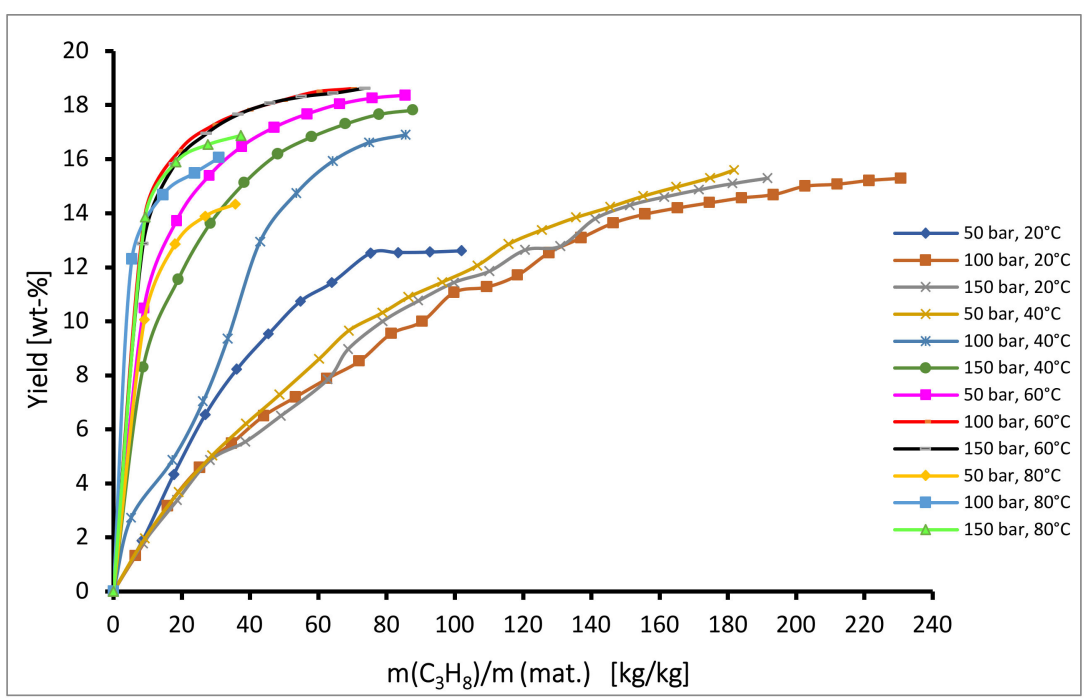

Figure 3. Kinetics of semi-continuous extraction of hops with propane.

When extracting with $\mathrm{SF}_{6}$ as solvent the total yields were minimal, ranging only between $0.5 \%$ and $0.9 \%$. The highest yield was obtained at $60{ }^{\circ} \mathrm{C}$ and pressure $150 \mathrm{bar}$, as can be seen from Figure 4 . It is unclear why $\mathrm{SF}_{6}$ was so inefficient as a solvent, and clearly density plays a role, however further experiments may be required to understand why in this case it was worse by a factor of 10 .

\subsection{Mathematical Modelling of Kinetic Curves}

Extraction kinetic curves for hop by the solvents investigated were analysed by a two-site kinetic model, that considers the presence of two parallel diffusion processes inside the solid; one faster, where the solute is transferred from the surface of the solid particle to the bulk of solvent and one slower, where the effective diffusion of solute inside the pores of solid particle is controlling the extraction rate. In between the two is a transition area where both processes can affect the extraction rate. In later stages of the extraction, only the second term on the right hand of Equation (5) remains significant, while in earlier stages of the extraction, the second exponential term is close to unity. 


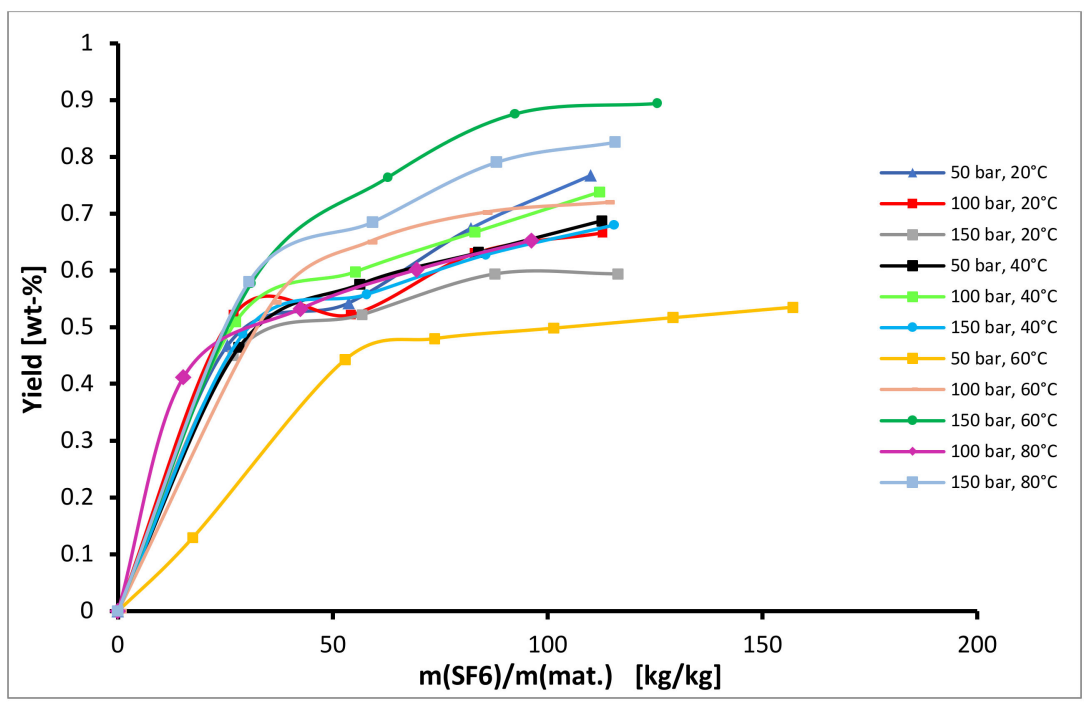

Figure 4. Kinetics of semi-continuous extraction of hops with $\mathrm{SF}_{6}$.

When modelling, the value of $m_{0}$ was set equal to the maximum extraction yield achieved by specific solvent, i.e., $m_{0}$ for $\mathrm{CO}_{2}$ was $13 \mathrm{mg} / \mathrm{g}$; for propane $20 \mathrm{mg} / \mathrm{g}$; for DME $26 \mathrm{mg} / \mathrm{g}$ and for SF6 $1 \mathrm{mg} / \mathrm{g}$.

The adjustable parameters obtained from best fitting of experimental curves for both extraction rate periods and deviation of the model from the data (AARD) are presented in Table 1.

For $\mathrm{CO}_{2}$ the experimentally obtained kinetic curves could be described by a oneextraction rate constant model, while for other solvents the experimental data were fitted by a two-rate constant model. Modelling was performed by Microsoft Excel using Solver, so the objective function (AARD) was minimized by adjusting the estimated parameters.

The agreement of calculated and experimental extraction curves can be observed in Figure 5 for $\mathrm{CO}_{2}$, in Figure 6 for propane, in Figure 7 for DME and in Figure 8 for $\mathrm{SF}_{6}$, respectively.

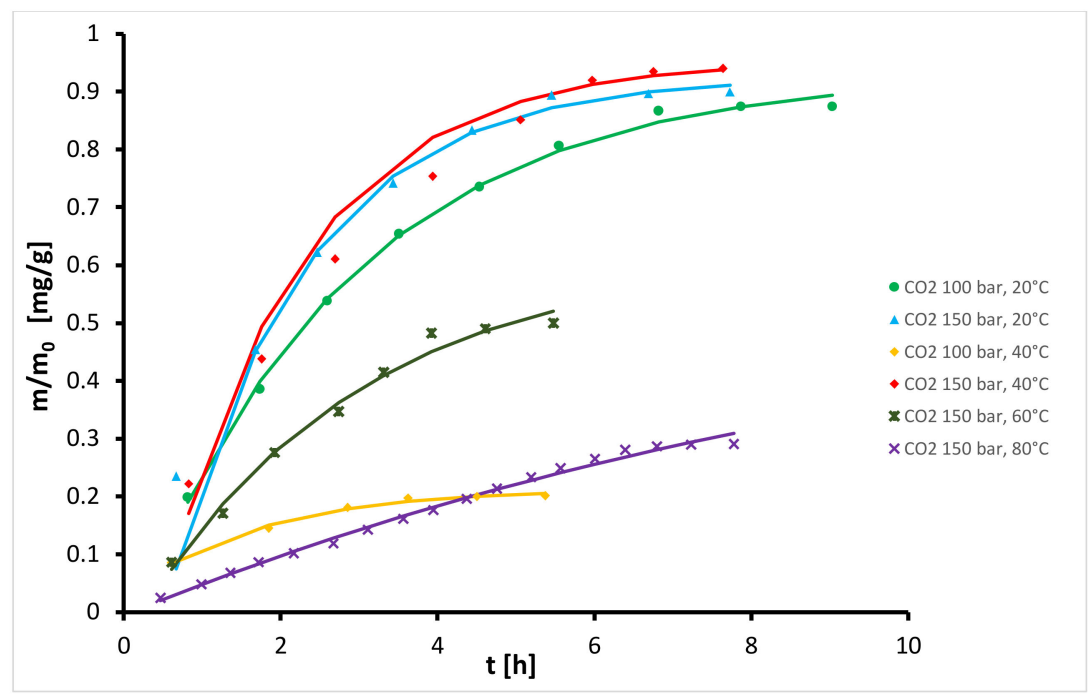

Figure 5. Experimental (symbols) and modelled (lines) kinetic curves for the extraction with $\mathrm{CO}_{2}$ as solvent. 


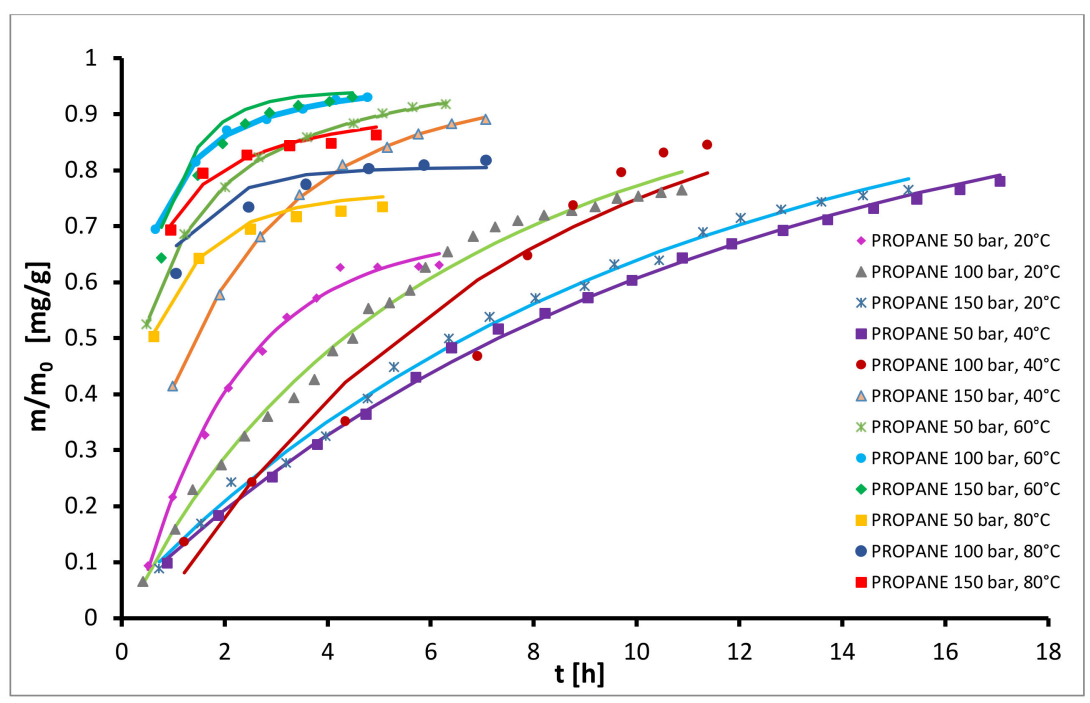

Figure 6. Experimental (symbols) and modelled (lines) kinetic curves for extraction with propane as solvent.

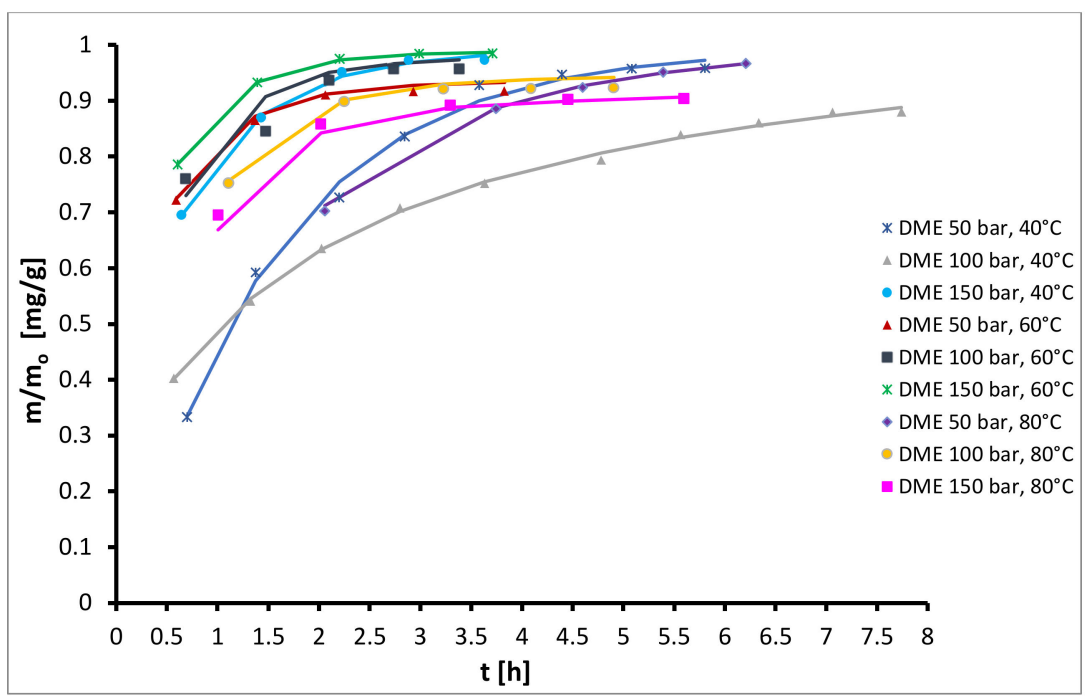

Figure 7. Experimental (symbols) and modelled (lines) kinetic curves for extraction with DME as solvent.

Overall, the mathematical model could fit adequately the extraction curves during all stages. AARD values, presented in Table 1, were from $0.06 \%$ to $9.10 \%$, except for liquid propane at $100 \mathrm{bar}$ and $40{ }^{\circ} \mathrm{C}$ where the AARD was $13.05 \%$. Extraction kinetic curves were analysed for both, fast and slow extraction rate periods and diffusion coefficients for both stages $D_{1}$ and $D_{2}$ were calculated.

For $\mathrm{CO}_{2}$, where one extraction rate period was considered by the model, results show that the diffusion coefficient at a constant pressure of 150 bar increases with decreasing temperature from $0.039 \times 10^{-7}\left(\mathrm{~m}^{2} / \mathrm{s}\right)$ at $80{ }^{\circ} \mathrm{C}$ to $0.248 \times 10^{-7}\left(\mathrm{~m}^{2} / \mathrm{s}\right)$ at $20{ }^{\circ} \mathrm{C}$. This behavior also corresponds to density variation of solvent which decreases with increasing temperature and therefore the solvent power of $\mathrm{CO}_{2}$ is decreased.

For extraction using propane as compressed solvent the effect of pressure is less notable than the effect of temperature. The propane is in the compressed liquid state over the entire experimental range, and the changing in density with the variation of pressure is less conspicuous. It can be noticed that extraction with propane is much faster than that with $\mathrm{CO}_{2}$ although both act as selective solvents for the extraction of non-polar compounds. The main reason for the temperature effect over the extraction performance 
is that by increasing the temperature, the density of the solvent decreases, reducing the solvation capacity. On the other hand, by increasing the pressure at a constant temperature in a subcritical state, propane diffusion into the matrix is influenced by the increase in its density and viscosity.

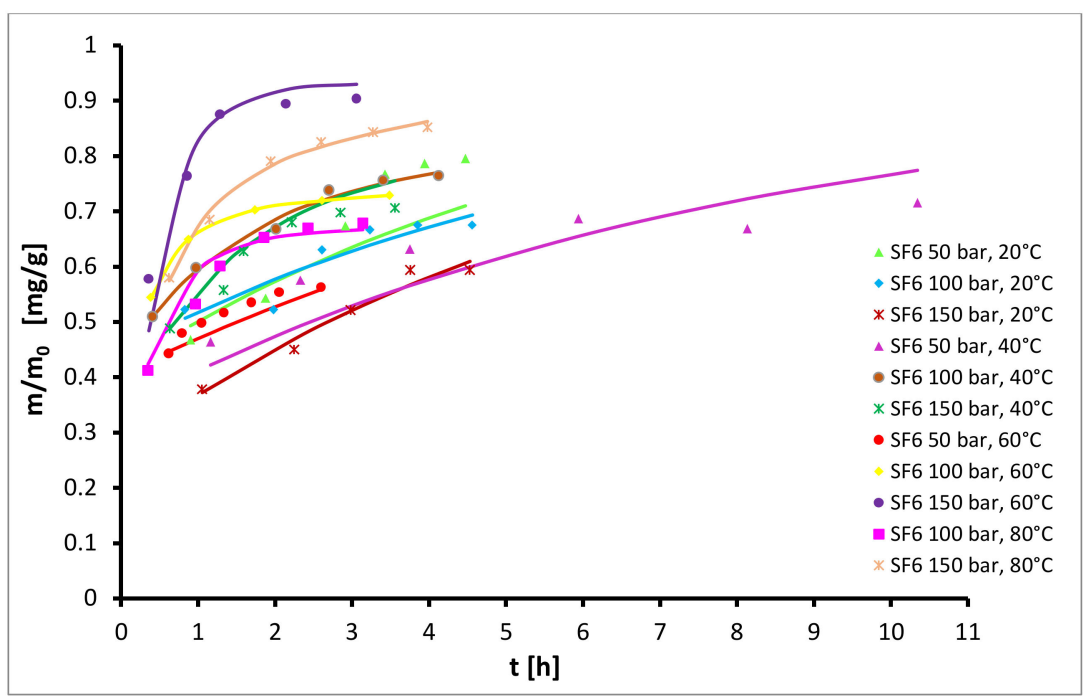

Figure 8. Experimental (symbols) and modelled (lines) kinetic curves for extraction with $\mathrm{SF}_{6}$ as solvent.

High extraction rate was observed at $60^{\circ} \mathrm{C}$ and 100 bar and $60{ }^{\circ} \mathrm{C}$ and 150 bar where it is obvious that the process is controlled by diffusion from the particle surface. Also the fraction of solute extracted in the first period ( 0.651 at 100 bar and 0.640 at 150 bar) was higher than in the second period, where the diffusion of solute inside the pores of solid particles to the particle surface is controlling the extraction rate.

By using DME as extraction solvent, much higher rates of extraction and superior yields were obtained. The highest extraction rate was observed at $60^{\circ} \mathrm{C}$ and 150 bar where also the highest yield was obtained. The diffusion coefficient $D_{1}$ at this condition was $0.736 \times 10^{-7}\left(\mathrm{~m}^{2} / \mathrm{s}\right)$ and was higher than $D_{2}$ obtained for the second period which was $0.329 \times 10^{-8}\left(\mathrm{~m}^{2} / \mathrm{s}\right)$.

From Figure 4 it can be observed the extraction with $\mathrm{SF}_{6}$ was not efficient and very low yields, lower than $0.9 \%$, were obtained at all experimental conditions. The highest diffusion coefficient $D_{1}$ was obtained at $60^{\circ} \mathrm{C}$ and $150 \mathrm{bar}$, where also the highest yield was observed.

\subsection{HPLC Analysis of Hop Extracts}

The concentrations of $\alpha$-acids and $\beta$-acids in hop extracts obtained with $\mathrm{CO}_{2}$, propane, $\mathrm{SF}_{6}$ and DME are presented in Table 2 and Figure 9. The yields of $\alpha$ - and $\beta$-acids represent the wt- $\%$ of initial acids in raw materials that were extracted by solvent and were calculated using Equation (4). The results show that the concentration of both acid groups in extract was low in the case of $\mathrm{SF}_{6}$. In the case of $\mathrm{CO}_{2}$ and propane, the optimal concentrations of $\alpha$ and $\beta$ acids in extracts were obtained at condition, that also gave max. yield of extract. By using propane, the max. yield was higher as for $\mathrm{CO}_{2}$ and also the concentration of both acid groups, especially that of $\beta$ acids in propane extract was higher as in $\mathrm{CO}_{2}$ extract (1.1 times higher for $\alpha$ and 3.15 times higher for $\beta$ acids). In the case of DME, the highest extraction yields were obtained, however concentrations of acids in extracts were generally similar to propane extracts. When comparing the results for all solvents, the greatest concentration of $\alpha$ acids (9.6\%) was obtained in the extract derived by DME at $40{ }^{\circ} \mathrm{C}$ and 100 bar which also presented a high yield (22.9\%). The highest concentration of $\beta$ acids $(4.5 \%)$ was also obtained by DME, however at $60{ }^{\circ} \mathrm{C}$ and 50 bar with a yield of $23.9 \%$. Based on these 
results it can be concluded that the best solvent for the isolation of $\alpha$ and $\beta$ acids is DME, as it gives the highest extraction yields and the highest concentrations of acids in extracts.

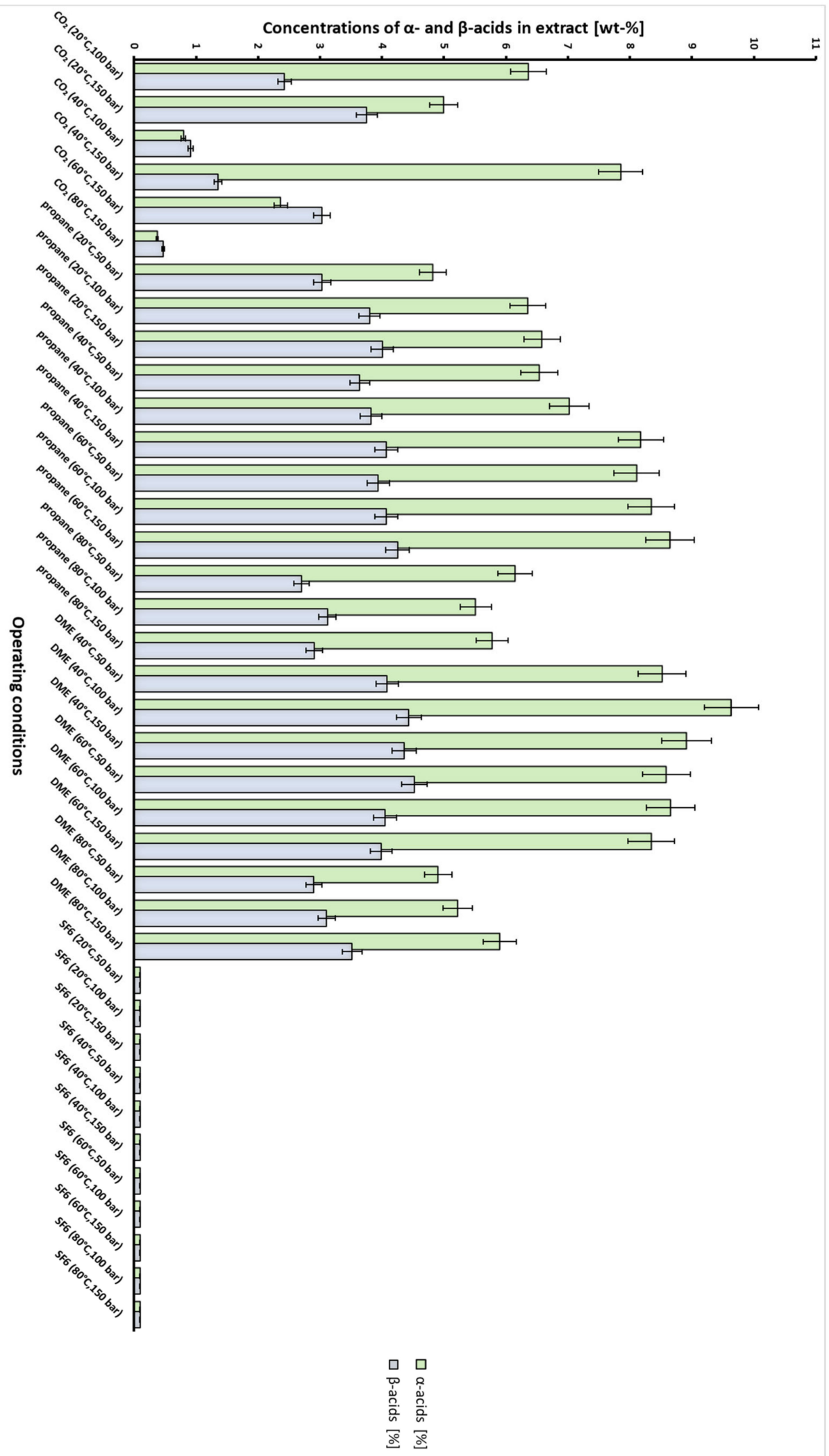

Figure 9. Weight fraction of $\alpha$ - and $\beta$-acids in extracts obtained by semicontinuous extraction of hops with dense gases at different operating conditions with standard deviation (SD) values. 
The extraction efficiency of $\alpha$-acids and $\beta$-acids as indicated by the acid yield was the highest in the case of DME, with yields higher than $95 \%$ for both acids at specific conditions were obtained, followed by propane, where the max. yield was $87.6 \%$ for $\alpha$-acids and $90.5 \%$ for $\beta$-acids, respectively. In the case of $\mathrm{CO}_{2}$ the yields of both acids were around $79.7 \%$ at specific conditions while for $\mathrm{SF}_{6}$, the yields were below $0.01 \%$. Chromatogram specimen of Aurora variety hop essential oils derived from HPLC analysis can be seen in Figure 10.

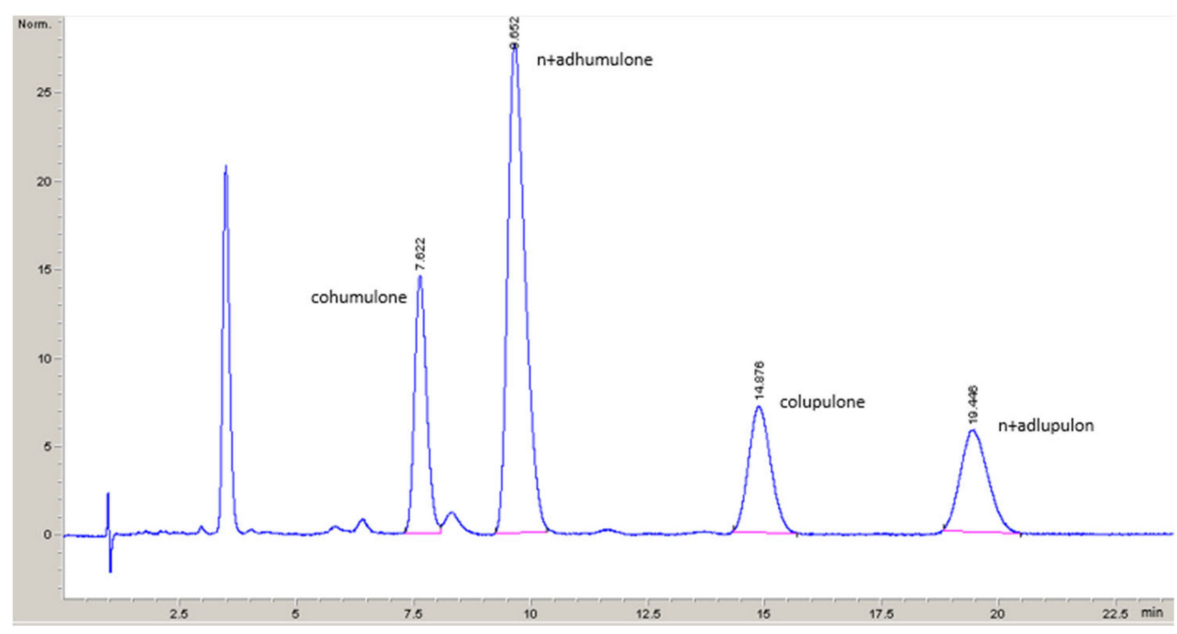

Figure 10. HPLC analysis chromatogram specimen of Aurora variety hop essential oils.

\section{Conclusions}

This study demonstrates various non-conventional extractions of Aurora variety Slovenian hops (Humulus lupulus L.). The solvents were selected based on their differing polarity. $\mathrm{CO}_{2}$, propane and $\mathrm{SF}_{6}$ were used as non-polar solvents and $\mathrm{DME}$ as a polar solvent. The best extraction was achieved using DME at $60{ }^{\circ} \mathrm{C}$ and 150 bar, with a global yield of $25.6 \%$. DME also showed a high variability with temperature and pressure both having a remarkable effect on the extraction yield and also on max. concentration of both acids. The highest concentration of $\alpha$-acids was $9.6 \%\left(40{ }^{\circ} \mathrm{C}, 100\right.$ bar $)$ and $\beta$-acids $4.5 \%$ $\left(60{ }^{\circ} \mathrm{C}, 50\right.$ bar). In this study, propane was the second-best solvent regarding extraction yield (18.7\% under operating conditions $60^{\circ} \mathrm{C}$ and 150 bar) and the concentrations of both $\alpha$ - and $\beta$-acids were also the highest ( $8.7 \%$ of $\alpha$-acids and $4.3 \%$ of $\beta$-acids). With $\mathrm{CO}_{2}$ the maximum yield (12.2\%) was reached at $40{ }^{\circ} \mathrm{C}$ and 150 bar with a max. concentration of $\alpha$-acids at $7.9 \% . \mathrm{SF}_{6}$ proved to be a very poor solvent for extracting hop resins, with a maximum extraction yield of only $0.9 \%$ at $60{ }^{\circ} \mathrm{C}$ and 150 bar. The extraction kinetics were modelled by the two-site kinetic model and good agreement between experimental data and model predictions was observed with percent average absolute relative deviation in the range of $0.06 \%$ to $13.05 \%$. The challenges to be faced using DME for further development of the process are around regulatory acceptance and overcoming safety issues concerning the flammability.

\section{Materials and Methods}

\subsection{Materials}

The hop pellets used in this study were supplied by Hmezad exim d.d. (Žalec, Slovenia). The cones of the hop cultivar Aurora were collected in Slovenia between the 23 and 30 August, air dried at 60 degrees and compressed into pellets. These were then purged with inert gas $\mathrm{N}_{2}$ and sealed into laminated polythene/metallised polyester bags. Pellets were stored out of sunlight in storage between +1 and $+4{ }^{\circ} \mathrm{C}$ to prevent excessive oxidation and oxidation of hop resins and essential oils. The composition of hop resins in raw material (pellets) was: total $\alpha$-acids $9.9 \%$ and total $\beta$-acids $4.7 \%$, determined according to Analytica-EBC 7.7 method [44]. 
CO2 (>99.5\% purity) was obtained from Messer Slovenija d.o.o. (Ruše, Slovenia). Propane ( $>99.5 \%$ purity) and DME ( $>99.5 \%$ purity) were obtained from Linde plin d.o.o. (Celje, Slovenia). $\mathrm{SF}_{6}(>99.5 \%$ purity) was purchased from Istrabenz d.d. (Koper, Slovenia). All chemicals used for HPLC analysis were purchased from Sigma Aldrich (Taufkirchen, Germany).

\subsection{Equipment and Experimental Procedures}

\subsubsection{Methods for Characterization of Material}

The pellets were ground in a domestic grinder after being in refrigerated storage for a month. Sieve analysis was performed to separate the fractions and to obtain homogeneous particles. The median particle size of ground hop pellets, determined from particle size distribution curves (frequency and cumulative arithmetic) was $1300 \mu \mathrm{m}$. The moisture content of extracts and raw material was determined using standard Analytica-EBC method 7.2 (Analytica-EBC 2007) [45]. The moisture content was considered in all calculations so yields and concentrations are expressed on a dry basis.

\subsubsection{Sub- and Supercritical Fluid Extraction (SFE)}

The experiments using different solvents were performed by a semi-continuous flow apparatus [46] (Figure 11). The maximum operating pressure and temperature of apparatus were 200 bar and $100{ }^{\circ} \mathrm{C}$, respectively. The extractor $(\mathrm{V}=60 \mathrm{~mL})$ was charged with approximately $45 \mathrm{~g}$ of ground material. The temperature of the water bath was regulated and maintained at a constant value $\left( \pm 0.5^{\circ} \mathrm{C}\right.$; LAUDA DR. R. Wobster GmbH \& Co. KG, Lauda Königshofen, Germany). The apparatus was purged first with nitrogen and later with the gas used for extraction. Liquefied gas was continuously pumped with a highpressure syringe pump (Pmax = 200 bar; ISCO, Louisville, KY, USA) through the preheating coil and over the bed of sample in the extractor. The flow rate of solvent, measured at room temperature and atmospheric pressure, was approximately $0.20 \mathrm{~kg} / \mathrm{h}$, respectively. The solvent flow rate was measured with a flow meter (Elster Handel GmbH, Mainz, Germany). The product precipitated in the separator (glass tube), where the separation was performed at $1 \mathrm{bar}$ and at a temperature of $20^{\circ} \mathrm{C}$. The product collected in the glass tube was weighed $( \pm 0.1 \mathrm{mg})$ and yield was calculated. The density of the gas inside the extractor $(\rho)$ was obtained from the NIST Chemistry WebBook, for $\mathrm{CO}_{2}$, propane and $\mathrm{SF}_{6}$ [47]. The density of DME was calculated with Peng-Robinson equation of state using the Aspen Plus process simulation software.

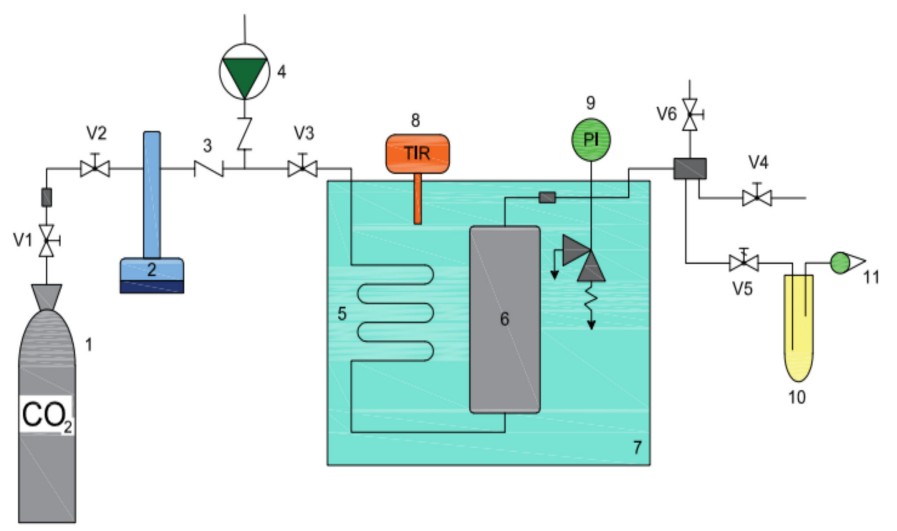

Figure 11. Schematic diagram of the high-pressure extraction apparatus (1-gas tank, 2-high pressure pump, 3-check valve, 4-HPLC pump, 5-gas heating tube, 6-autoclave, 7-water tank with heater, 8-temperature regulator, 9-manometer pressure gauge, 10-extract, 11-rotameter, V1-V6-valves).

\subsubsection{High-Performance Liquid Chromatography (HPLC) Analysis of Extract}

According to Analytica-EBC 7.7 method [44] high performance liquid chromatography (HPLC) was employed to determine the $\alpha$ - and $\beta$-acids in extracts with liquid 
chromatograph Agilent 1200 Series (Agilent, Palo Alto, CA, USA). $0.5 \mathrm{~g}$ of hop extract was diluted with $50 \mathrm{~mL}$ methanol and $5 \mathrm{~mL}$ of this solution was additionally diluted in $50 \mathrm{~mL}$ of methanol. Extracts were filtered through disposable syringe filters, Chromafil Xtra PET-45/25 (Macherey-Nagel, Düren, Germany) and $10 \mu \mathrm{L}$ injection loop on HPLC injector was used. The separation was achieved on Nucleodur 5-100 C18, $125 \times 4 \mathrm{~mm}$ HPLC analysis column (Macherey-Nagel). Isocratic mobile phase constituted from distilled water, methanol (J.T. Baker, Phillipsburg, NJ, USA) and 85\% aqueous solution of orthophosphoric acid (Merck, Darmstadt, Germany) in a ratio of 775/210/9 (v/v/v) was used and the detection was carried out with a diode array detector (DAD) set at $314 \mathrm{~nm}$. The quantification was done by the external standard ICE4 (NATECO2, Wolnzach, Germany). All solvents were of analytical grade purity.

The content of individual fractions ( $\alpha$-and $\beta$-acids) in the extract was calculated by the following equation:

$$
c_{i v}=\frac{m_{s} c_{i s} A_{i v}}{m_{v} A_{i s}}
$$

where $c_{i v}$ stands for the concentration of component $i$ in sample expressed in weight $\%, m_{s}$ is the weight of the calibration standard in grams, $c_{i s}$ is the concentration of component $i$ in standard, $A_{i v}$ is the peak area of component $i$ in the sample, $m_{v}$ is weight of the sample and $A_{i s}$ means surface of the peak $i$ of calibration standard. The content of $\alpha$-acids is calculated as the sum of the two fractions: cohumulone (coh), nhumulone and adhumulone together ( $\mathrm{nh}+\mathrm{adh})$; and the content of $\beta$-acids as the sum of the two fractions: colupulone (col), nlupulone and adlupulone together $(\mathrm{nl}+\mathrm{adl})$ :

$$
\begin{gathered}
c_{\alpha}=c_{(c o h)}+c_{(n h+a d h)} \\
c_{\beta}=c_{(c o l)}+c_{(n l+a d l)}
\end{gathered}
$$

The concentrations of $\alpha$ - and $\beta$-acids are expressed as the $\mathrm{W} \%$ of acids determined in the extract and the efficiency of extraction is expressed in grams of acids per $100 \mathrm{~g}$ of material.

Yields of $\alpha$ - and $\beta$-acids which represent the wt- $\%$ of discharged acids in relation to the initial concentration of acids in raw material are calculated using Equation (4):

$$
\operatorname{Yield}_{(\alpha, \beta-a c i d s)}=\frac{m_{(\alpha, \beta-a c i d s) \text { in extract }}}{m_{(\alpha, \beta-a c i d s) \text { in raw material }}} * 100 \%
$$

\subsubsection{Mathematical Model}

Supercritical extraction processes are based on diffusion. The solvent must diffuse into the matrix, and the extracted material diffuse out of the matrix into the solvent. The extraction kinetics were modelled by the so-called "two-site kinetic model". The model is an extension of the "one-site kinetic model", mostly referred as Crank's hot ball diffusion model, which is based on Fick's second law of diffusion [48,49]. Experimental extraction curves were analysed considering a fast and a slow extraction period relevant to two different solute fractions. One fraction of the solute is quickly released and another fraction in the matrices is slowly released. This two-stages diffusion mechanism can be written for the ratio of mass of analyte removed after time $t$ to the initial mass, $m_{0}$, consisting of two first-order expressions, as follows:

$$
\frac{m_{t}}{m_{0}}=1-k_{1} \exp \left(-k_{2} t\right)-k_{3} \exp \left(-k_{4} t\right)
$$

in which $m_{t}$ is the mass of the analyte removed by the extraction fluid after time $t(\mathrm{mg} / \mathrm{g})$, $m_{0}$ the total initial mass of analyte in the matrix $(\mathrm{mg} / \mathrm{g}), m_{t} / m_{0}$ the fraction of the solute extracted after time $t$, a certain fraction $\left(k_{1}\right)$ desorbs at a fast rate determined by $k_{2}$ and the other fraction $\left(k_{3}\right)$ defined by $k_{4}$ which desorbs at a slower rate [50-52]. It is important to 
know that this model relies solely on time and it does not include any factor describing extraction flow-rate [53].

The Microsoft Excel Solver regression routine was used to fit the extraction data to Equation (5). The fit parameters were $k_{1}, k_{2}, k_{3}$ and $k_{4}$, as previously described.

The model presented by Equation (5) is practically the same as diffusion model for solid-liquid extraction of spherical particles proposed by Crank [54] (Equation (6)):

$$
\frac{m_{0}-m}{m_{0}}=\frac{6}{\pi^{2}}\left[f_{1} \exp \left\{-\frac{\pi^{2} D_{1}}{R^{2}} t\right\}+f_{2} \exp \left\{-\frac{\pi^{2} D_{2}}{R^{2}} t\right\}\right]
$$

where $R$ is the sphere particles' radius and $f_{1}$ and $f_{2}$ are the fractions of the solute, which are extracted with diffusion coefficients $D_{1}$ and $D_{2}$, respectively [48]. Therefore, from results obtained by Equation (5) for constants $k_{2}$ and $k_{4}$ diffusion coefficients $D_{1}$ and $D_{2}$ were calculated.

The average absolute relative deviation, for all experimental data, was calculated using the following expression:

$$
\operatorname{AARD}(\%)=\frac{100}{N} \sum_{i=1}^{N} \frac{\mid \text { yield }_{\text {calc }}-\text { yield }_{\exp } \mid}{\text { yield }_{\exp }}
$$

Author Contributions: K.B. conceived the study, designed and performed the experiments, and writing_original manuscript; M.Š. participated in data curation and mathematical modelling, provided comments to the paper; I.J.K. performed HPLC analysis; Ž.K. designed and supervised the work-flow of the experiment. All authors have read and agreed to the published version of the manuscript.

Funding: This research was supported from the Slovenian Research Agency within the frame of Programme P2-0046 (Separation Processes and Production Design). The operational part was financed by the European Union, European Social Fund.

Conflicts of Interest: The authors declare no conflict of interest.

\section{References}

1. Karabín, M.; Hudcová, T.; Jelínek, L.; Dostálek, P. Biologically Active Compounds from Hops and Prospects for Their Use. Compr. Rev. Food Sci. Food Saf. 2016, 15, 542-567. [CrossRef]

2. Awasthi, P.; Kocábek, T.; Mishra, A.K.; Nath, V.S.; Shrestha, A.; Matoušek, J. Establishment of CRISPR/Cas9 mediated targeted mutagenesis in hop (Humulus lupulus). Plant Physiol. Biochem. 2021, 160, 1-7. [CrossRef]

3. Afonso, S.; Arrobas, M.; Pereira, E.L.; Rodrigues, M.Â. Recycling nutrient-rich hop leaves by composting with wheat straw and farmyard manure in suitable mixtures. J. Environ. Manag. 2021, 284, 112105. [CrossRef] [PubMed]

4. Economic Commission. Summary Reports. In Proceedings of the International Hop Growers' Convention, Online. 9 November 2020.

5. Mishra, A.K.; Kocábek, T.; Nath, V.S.; Awasthi, P.; Shrestha, A.; Killi, U.K.; Jakse, J.; Patzak, J.; Krofta, K.; Matoušek, J. Dissection of Dynamic Transcriptome Landscape of Leaf, Bract, and Lupulin Gland in Hop (Humulus lupulus L.). Int. J. Mol. Sci. 2020, 21, 233. [CrossRef]

6. $\quad$ Bocquet, L.; Rivière, C.; Dermont, C.; Samaillie, J.; Hilbert, J.-L.; Halama, P.; Siah, A.; Sahpaz, S. Antifungal activity of hop extracts and compounds against the wheat pathogen Zymoseptoria tritici. Ind. Crop. Prod. 2018, 122, 290-297. [CrossRef]

7. Milligan, S.; Kalita, J.; Pocock, V.; Heyerick, A.; de Cooman, L.; Rong, H.; de Keukeleire, D. Oestrogenic Activity of the Hop Phyto-Oestrogen, 8-Prenylnaringenin. Reprod. Camb. Engl. 2002, 123, 235-242. [CrossRef]

8. Arruda, T.R.; Pinheiro, P.F.; Silva, P.I.; Bernardes, P.C. A new perspective of a well-recognized raw material: Phenolic content, antioxidant and antimicrobial activities and $\alpha$ - and $\beta$-acids profile of Brazilian hop (Humulus lupulus L.) extracts. LWT 2021, 141, 110905. [CrossRef]

9. Rutnik, K.; Hrnčič, M.K.; Košir, I.J. Hop Essential Oil: Chemical Composition, Extraction, Analysis, and Applications. Food Rev. Int. 2021, 37, 1-23. [CrossRef]

10. Holubkova, A.; Mosovska, S.; Baloghová, B.; Šturdík, E. Hop pellets as an interesting source of antioxidant active compounds. Potravin. Slovak J. Food Sci. 2013, 7, 53-57. [CrossRef]

11. Lafontaine, S.; Varnum, S.; Roland, A.; Delpech, S.; Dagan, L.; Vollmer, D.; Kishimoto, T.; Shellhammer, T. Impact of harvest maturity on the aroma characteristics and chemistry of Cascade hops used for dry-hopping. Food Chem. 2019, 278, 228-239. [CrossRef] 
12. Schönberger, C.; Kostelecky, T. 125th Anniversary Review: The Role of Hops in Brewing. J. Inst. Brew. 2011, 117, $259-267$. [CrossRef]

13. Laws, D.R.J. Hop Extracts-A Review. J. Inst. Brew. 1981, 87, 24-29. [CrossRef]

14. Caballero, I.; Blanco, C.A.; Porras, M. Iso- $\alpha$-acids, bitterness and loss of beer quality during storage. Trends Food Sci. Technol. 2012, 26, 21-30. [CrossRef]

15. Steenackers, B.; de Cooman, L.; de Vos, D. Chemical transformations of characteristic hop secondary metabolites in relation to beer properties and the brewing process: A review. Food Chem. 2015, 172, 742-756. [CrossRef]

16. Tyśkiewicz, K.; Gieysztor, R.; Konkol, M.; Szałas, J.; Rój, E. Essential Oils from Humulus lupulus scCO 2 Extract by Hydrodistillation and Microwave-Assisted Hydrodistillation. Molecules 2018, 23, 2866. [CrossRef] [PubMed]

17. Krottenthaler, M. Hops. In Handbook of Brewing; John Wiley \& Sons: Hoboken, NJ, USA, 2009; pp. 85-104. ISBN 978-3-527-62348-8.

18. Biendl, M.; Pinzl, C. Hops and Health: Uses, Effects, History, 2nd updated ed.; German Hop Museum: Wolnzach, Germany, 2013; ISBN 978-3-929749-10-6.

19. Matsui, H.; Inui, T.; Oka, K.; Fukui, N. The influence of pruning and harvest timing on hop aroma, cone appearance, and yield. Food Chem. 2016, 202, 15-22. [CrossRef] [PubMed]

20. Daoud, I.S.; Kusinski, S. Process Aspects of the Extraction of Hops with Liquid Carbon Dioxide. J. Inst. Brew. 1986, 92, 559-567. [CrossRef]

21. Kupski, S.C.; Klein, E.J.; Silva, E.A.; Palú, F.; Guirardello, R.; Vieira, M.G.A. Mathematical modeling of supercritical $\mathrm{CO}_{2}$ extraction of hops (Humulus lupulus L.). J. Supercrit. Fluids 2017, 130, 347-356. [CrossRef]

22. Knez, Ž.; Markočič, E.; Leitgeb, M.; Primožič, M.; Hrnčič, M.K.; Škerget, M. Industrial applications of supercritical fluids: A review. Energy 2014, 77, 235-243. [CrossRef]

23. Hrnčič, M.K.; Španinger, E.; Košir, I.J.; Knez, Ž.; Bren, U. Hop Compounds: Extraction Techniques, Chemical Analyses, Antioxidative, Antimicrobial, and Anticarcinogenic Effects. Nutrients 2019, 11, 257. [CrossRef]

24. Pereira, C.G.; Meireles, M.A.A. Supercritical Fluid Extraction of Bioactive Compounds: Fundamentals, Applications and Economic Perspectives. Food Bioprocess Technol. 2010, 3, 340-372. [CrossRef]

25. Solana, M.; Boschiero, I.; dall'Acqua, S.; Bertucco, A. Extraction of bioactive enriched fractions from Eruca sativa leaves by supercritical $\mathrm{CO}_{2}$ technology using different co-solvents. J. Supercrit. Fluids 2014, 94, 245-251. [CrossRef]

26. Shabkhiz, M.A.; Eikani, M.H.; Sadr, Z.B.; Golmohammad, F. Superheated water extraction of glycyrrhizic acid from licorice root. Food Chem. 2016, 210, 396-401. [CrossRef]

27. Fetzer, D.L.; Cruz, P.N.; Hamerski, F.; Corazza, M.L. Extraction of baru (Dipteryx alata vogel) seed oil using compressed solvents technology. J. Supercrit. Fluids 2018, 137, 23-33. [CrossRef]

28. Czaikoski, K.; Mesomo, M.C.; Scheer, A.D.P.; Santa, O.R.D.; Queiroga, C.L.; Corazza, M.L. Kinetics, composition and biological activity of Eupatorium intermedium flower extracts obtained from $\mathrm{scCO}_{2}$ and compressed propane. J. Supercrit. Fluids 2015, 97, 145-153. [CrossRef]

29. Mesomo, M.C.; Scheer, A.D.P.; Perez, E.; Ndiaye, P.M.; Corazza, M.L. Ginger (Zingiber officinale R.) extracts obtained using supercritical $\mathrm{CO}_{2}$ and compressed propane: Kinetics and antioxidant activity evaluation. J. Supercrit. Fluids 2012, 71, 102-109. [CrossRef]

30. Correa, M.; Bombardelli, M.C.M.; Fontana, P.D.; Bovo, F.; Messias-Reason, I.J.; Maurer, J.B.B.; Corazza, M.L. Bioactivity of extracts of Musa paradisiaca L. obtained with compressed propane and supercritical $\mathrm{CO}_{2}$. J. Supercrit. Fluids 2017, 122, 63-69. [CrossRef]

31. Teixeira, G.L.; Ghazani, S.M.; Corazza, M.L.; Marangoni, A.G.; Ribani, R.H. Assessment of subcritical propane, supercritical CO 2 and Soxhlet extraction of oil from sapucaia (Lecythis pisonis) nuts. J. Supercrit. Fluids 2018, 133, 122-132. [CrossRef]

32. Guedes, A.R.; de Souza, A.R.C.; Zanoelo, E.F.; Corazza, M.L. Extraction of citronella grass solutes with supercritical CO compressed propane and ethanol as cosolvent: Kinetics modeling and total phenolic assessment. J. Supercrit. Fluids 2018, 137, 16-22. [CrossRef]

33. Catchpole, O.J.; Tallon, S.J.; Grey, J.B.; Fenton, K.; Fletcher, K.; Fletcher, A.J. Extraction of Lipids from Aqueous Protein-Rich Streams using Near-Critical Dimethylether. Chem. Eng. Technol. 2007, 30, 501-510. [CrossRef]

34. Knez, Ž.; Ilić, L.; Škerget, M.; Kotnik, P. High-Pressure Solubility Data for Palm Oil-SF6and Coconut Oil-SF6Systems. J. Chem. Eng. Data 2010, 55, 5829-5833. [CrossRef]

35. Ilič, L.; Škerget, M.; Hrncic, M.K.; Knez, Ž. Phase behavior of sunflower oil and soybean oil in propane and sulphur hexafluoride. J. Supercrit. Fluids 2009, 51, 109-114. [CrossRef]

36. Biendl, M.; Engelhard, B.; Forster, A.; Gahr, A.; Lutz, A.; Mitter, W.; Schmidt, R.; Schönberger, C. Hops: Their Cultivation, Composition and Usage; Fachverlag Hans Carl GmbH: Nuremberg, Germany, 2015; Volume 2014, ISBN 978-3-418-00904-9.

37. Campos, L.M.A.S.; Michielin, E.M.Z.; Danielski, L.; Ferreira, S.R.S. Experimental data and modeling the supercritical fluid extraction of marigold (Calendula officinalis) oleoresin. J. Supercrit. Fluids 2005, 34, 163-170. [CrossRef]

38. Del Valle, J.M.; Rivera, O.; Teuber, O.; Palma, M.T. Supercritical $\mathrm{CO}_{2}$ extraction of Chilean hop (Humulus lupulus) ecotypes. J. Sci. Food Agric. 2003, 83, 1349-1356. [CrossRef]

39. Vargas, R.M.F.; Cassel, E.; Gomes, G.M.F.; Longhi, L.G.S.; Atti-Serafini, L.; Atti-Santos, A.C. Supercritical extraction of carqueja essential oil: Experiments and modeling. Braz. J. Chem. Eng. 2006, 23, 375-382. [CrossRef]

40. Zancan, K.C.; Marques, M.O.M.; Petenate, A.J.; Meireles, M.A.A. Extraction of ginger (Zingiber officinale Roscoe) oleoresin with $\mathrm{CO}_{2}$ and co-solvents: A study of the antioxidant action of the extracts. J. Supercrit. Fluids 2002, 24, 57-76. [CrossRef] 
41. Sovová, H.; Jez, J.; Bártlová, M.; St’Astová, J. Supercritical carbon dioxide extraction of black pepper. J. Supercrit. Fluids 1995, 8 , 295-301. [CrossRef]

42. Langezaal, C.R.; Chandra, A.; Katsiotis, S.T.; Scheffer, J.J.C.; De Haan, A.B. Analysis of supercritical carbon dioxide extracts from cones and leaves of a Humulus lupulus L cultivar. J. Sci. Food Agric. 1990, 53, 455-463. [CrossRef]

43. Veiga, B.A.; Hamerski, F.; Clausen, M.P.; Errico, M.; Scheer, A.D.P.; Corazza, M.L. Compressed fluids extraction methods, yields, antioxidant activities, total phenolics and flavonoids content for Brazilian Mantiqueira hops. J. Supercrit. Fluids 2021, 170, 105155. [CrossRef]

44. European Brewery Convention. Analytica-EBC, Section 7 Hops, Method 7.7; Hans Carl Getränke Fachverlag: Nürenberg, Germany, 2007.

45. European Brewery Convention. Analytica-EBC, Section 7 Hops, Method 7.2; Hans Carl Getränke Fachverlag: Nürenberg, Germany, 2007.

46. Hadolin, M.; Škerget, M.; Knez, Z.; Bauman, D. High pressure extraction of vitamin E-rich oil from Silybum marianum. Food Chem. 2001, 74, 355-364. [CrossRef]

47. NIST. Nist Chemistry Webbook: Nist Standard Reference Database Number 69. Available online: https://webbook.nist.gov/ chemistry/ (accessed on 12 April 2021).

48. Skerget, M.; Bezjak, M.; Makovšek, K.; Knez, Z. Extraction of Lutein Diesters from Tagetes erecta using Supercritical $\mathrm{CO}_{2}$ and Liquid Propane. Acta Chim. Slov. 2010, 57, 60-65.

49. Aleksovski, S.A.; Sovova, H. Supercritical $\mathrm{CO}_{2}$ extraction of Salvia officinalis L. J. Supercrit. Fluids 2007, 40, 239-245. [CrossRef]

50. Anekpankul, T.; Goto, M.; Sasaki, M.; Pavasant, P.; Shotipruk, A. Extraction of anti-cancer damnacanthal from roots of Morinda citrifolia by subcritical water. Sep. Purif. Technol. 2007, 55, 343-349. [CrossRef]

51. Kubátová, A.; Jansen, B.; Vaudoisot, J.-F.; Hawthorne, S.B. Thermodynamic and kinetic models for the extraction of essential oil from savory and polycyclic aromatic hydrocarbons from soil with hot (subcritical) water and supercritical $\mathrm{CO}_{2}$. J. Chromatogr. A 2002, 975, 175-188. [CrossRef]

52. Machmudah, S.; Kondo, M.; Sasaki, M.; Goto, M.; Munemasa, J.; Yamagata, M. Pressure effect in supercritical $\mathrm{CO}_{2}$ extraction of plant seeds. J. Supercrit. Fluids 2008, 44, 301-307. [CrossRef]

53. Sovová, $\mathrm{H}$. Rate of the vegetable oil extraction with supercritical $\mathrm{CO}_{2}-\mathrm{I}$. Modelling of extraction curves. Chem. Eng. Sci. 1994, 49, 409-414. [CrossRef]

54. Crank, J.; Crank, E.P.J. The Mathematics of Diffusion; Oxford University Press: Oxford, UK, 1975; ISBN 978-0-19-853411-2. 